\title{
Numerical Research on Cutting Force and Fracture Morphology of Rock Plate with Two Sides Fixed and Two Sides Free
}

\author{
Zhenguo Lu $\mathbb{D}^{1,},{ }^{1,2}$ Qingliang Zeng $\mathbb{D}^{2,3}$ Zhaosheng Meng $\mathbb{D}^{4},{ }^{4}$ Zhiwen Wang $\mathbb{D}^{3}$ \\ and Guanshun Gao iD ${ }^{3}$ \\ ${ }^{1}$ College of Transportation, Shandong University of Science and Technology, Qingdao 266590, China \\ ${ }^{2}$ Shandong Province Key Laboratory of Mine Mechanical Engineering, Shandong University of Science and Technology, \\ Qingdao 266590, China \\ ${ }^{3}$ College of Mechanical and Electronic Engineering, Shandong University of Science and Technology, Qingdao 266590, China \\ ${ }^{4}$ State Key Laboratory of Mining Disaster Prevention and Control Cofounded by Shandong Province and the Ministry of Science \\ and Technology, Shandong University of Science and Technology, Qingdao 266590, China
}

Correspondence should be addressed to Zhaosheng Meng; skdmzs@163.com

Received 6 January 2020; Revised 8 May 2020; Accepted 16 May 2020; Published 29 May 2020

Academic Editor: Michele Brun

Copyright $\odot 2020$ Zhenguo Lu et al. This is an open access article distributed under the Creative Commons Attribution License, which permits unrestricted use, distribution, and reproduction in any medium, provided the original work is properly cited.

Conical pick is a diffusely applied cutting tool in rock excavation in the coal-mining industry. In order to enhance the capability of conical pick, a new rock cutting method based on increased free surface is proposed. To research the peak cutting force and fracture morphology, ANSYS/LS-DYNA is used to establish the conical pick and rock interaction model. To obtain the fracture morphology of rock plate, eroding contact, erosion element failure, and damage constitutive are considered in the numerical model. Mechanical properties test and rock plate cutting experiment are carried out to guarantee and verify the correctness of the numerical model. The width and height of rock plate influencing peak cutting force and fracture morphology are studied, and the stable peak cutting force is defined. Lower width and height contribute to more fragments in smaller dimension produced during the rock plate cutting process. Besides, higher skew angle leads to more fragments. The peak cutting force decreases with the increasing width and height of rock plate while reaching stable peak cutting force, and it reduces and then remains stable with the increasing cutting position and symmetrical with skew angle of zero degree.

\section{Introduction}

Coal is one of the most important energies all over the world. Mechanical excavators are widely used in coal mining. In the process of coal mining and roadway excavation, rock cutting often happens, where conical pick bears rather heavy loads, which leads to conical pick damage or wear. Research on rock cutting performance is very important for designing conical pick and reducing production cost.

In order to reveal the rock cutting mechanism and improve the cutting performance of conical pick, many scholars have conducted theoretical, experimental, and numerical research studies. The most classical and widely used theory is proposed by Evans [1], who proves that the tensile strength, compressive strength of rock, cone angle, and cutting depth of conical pick are the main factors influencing cutting force. He also points out the obvious defect of the cutting theory; that is, cutting force is not equal to zero when cone angle is zero degree. On this basis, Roxborough and Liu [2] improve Evans' cutting theory, who not only take friction angle into account but also redefine the influence of tensile strength, compressive strength, and tip angle of conical pick on cutting. Goktan theory considers that the main failure mode of rock is tensile failure, the influence of compressive strength on cutting force is ignored, and the friction angle is defined as $8.5^{\circ}$ [3]. Further, Goktan and Gunes [4] point out that Evans' cutting theory cannot be applied to asymmetrical rock cutting and they 
establish prediction equations of mean cutting force and peak cutting force based on semiempirical approach. Test of rocks with different compressive strengths has shown that the equation has statistical significance. Bao et al. [5] establish a new mechanics model based on penetration force and energy dissipation, which has been verified by tests. The mechanics model shows that cutting depth has a strong relationship with peak cutting force and external work done by the cutting force. Based on fracture mechanics, Li et al. [6] point out that peak cutting force does not appear at the moment of fragment formation, but at the moment of crack formation. The prediction model shows that peak cutting force has a strong relationship with fracture toughness and cutting depth. Yasar [7] shows that, based on the analysis of existing theories, it considers the influence of rock brittleness and tool rake angle on cutting force. In order to get closer to reality, a back-clearance angle correction function is added in the model. Results show that the ratio of peak cutting force to average cutting force is 2.45. Bilgin et al. [8] carry out experiments to research the compressive strength influencing rock cutting performance. Results show that the correlation between uniaxial compressive strengths is the best. Yasar and Yilmaz $[9,10]$ discuss the relationships between specific energy and other parameters in both relieved and unrelieved cutting modes to investigate the optimum cutting condition. By comparing theoretical and experimental values, it is found that the theoretical model should include friction angle, cone angle, and attack angle; meanwhile, ductile-brittle transition should be considered. Wang et al. [11] research cutting depth and angles related to conical pick influencing rock cutting performance and establish the productivity prediction model based on specific energy consumption. Yasar [12] carries out rock cutting tests with single conical pick and establishes a mathematical model, which points out that small-scale rock cutting tests is an effective approach to research the rock cutting performance. Li et al. [13] build a numerical model between rock and pick to investigate the mechanism of rock fragmentation and wear mechanism of pick itself. Wang et al. [14] study the confining stress and cutting parameters influencing hard rock fragmentation by using a conical pick in an experimental approach. Zhao et al. [15] employ ANSYS/LS-DYNA to investigate the variation of cutting force in spiral drum and interaction process and give the maximum stress that the alloy head endures for structural optimization. Wang et al. [16] develop a new rock constitutive model which can show rock damage and verify it by cutting tests. In recent years, the study of pick wear is also very popular. Liu et al. [17] study the wear mechanism of the conical pick, indicating that the cutter nearby compression area is subject to severe wear. Dewangan et al. [18] believe that, in rock and coal cutting process, the main types of conical pick wear mechanisms are coal/rock intermixing, plastic deformation, rock channel formation, and crushing and cracking. Yang et al. [19] show that the wear of picks increases with the increasing rotation angle and decreases with the cutting angle, and theoretical results have been verified by experimental results. Li et al. [13] employ the numerical approach to research the failure mode of rock and conical pick. In order to solve the problem of conical pick wear, methods of rock cutting by high-pressure water jets and rock cutting by thermal are proposed [20,21]. Comakli [22] points out that the conical pick wear has a strong relationship with water contents of rocks. However, the mechanical rock cutting method with cutting tool is the most reliable and widely used approach [23].

Considerable researches have been carried out in experimental, numerical, and theoretical approaches; however, new rock cutting methods are rarely proposed. Besides, the numerical method adopted in previous studies is unable to achieve the rock fracture morphology in three-dimensional numerical conditions. In the present paper, a new rock cutting method is put forward based on increased free surface. Rock plate cutting force and fracture morphology are studied by numerical simulation method in the new rock cutting approach. The mechanical properties of rock are tested, and the feasibility of numerical simulation method is verified by experiment.

\section{Methods}

2.1. Proposal of Tunnel Driving Scheme. Hard rock cutting often occurs in mine excavation. To improve the cutting ability of conical pick, increasing cutting power is the most common and effective approach. However, with the processing technology remaining the same as before, the conical pick wears seriously. To conquer the disadvantage of conical pick wear, the rock cutting method based on increased free surface is proposed. The diamond saw blades presented in Figure 1 are employed to slice the rock to obtain kerfs and rock plates shown in Figure 2. On this foundation, cutting head is applied to cut the rock plates with a certain cutting path. On the premise of ignoring the chamfer, the rock plate is a rectangular plate with three sides constrained and one side free. In the process of rock plate cutting, it is very likely to form two sides constrained and two sides free rock plate [24]. The main research content of the paper is carried out on the basis of the rock plate with two sides fixed and two sides free. The rock plate is cut by single conical pick, and the cutting performance is studied by numerical method. In order to guarantee the feasibility of the numerical method, verification experiment is carried out.

2.2. Numerical Model. The numerical simulation in this paper has two main purposes, one to obtain rock plate cutting force and the other to obtain the fracture morphology of rock plate. With three-dimensional numerical simulation methods, it is not difficult to acquire accurate cutting force. But the fracture morphology is very difficult to obtain with conventional three-dimensional simulation method. In the study, ANSYS/LS-DYNA (3D) is used to numerical simulation. The interaction model between single cutting tool and rock is presented in Figure 3. The rock consists of rock plate and base rock. The stationary rock plate is cut by the translational conical pick. In the paper, the wear of the conical pick is not considered, so it is set as a rigid body. Rock material is assigned by 


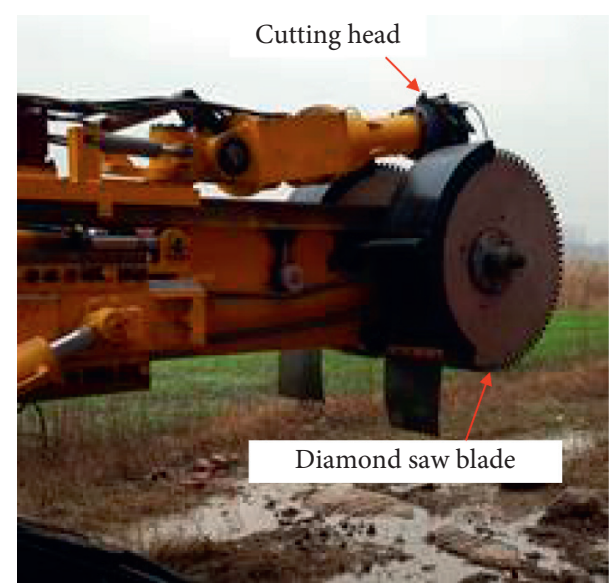

Figure 1: Cutting unit based on increased free surface cutting method.

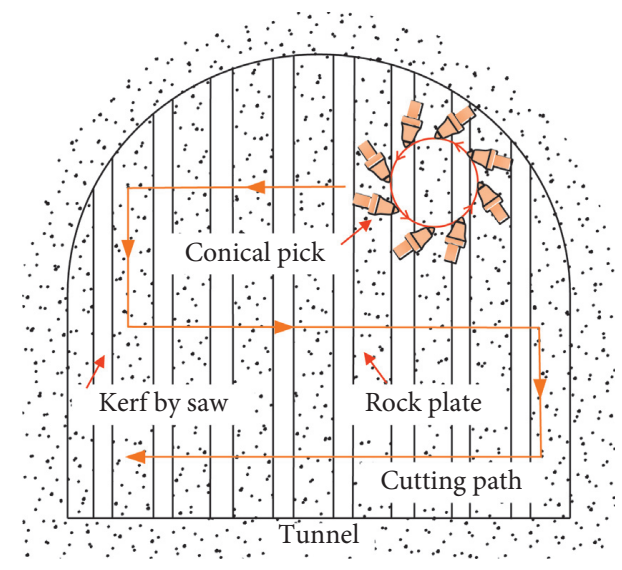

Figure 2: Diagram of roadway driving.

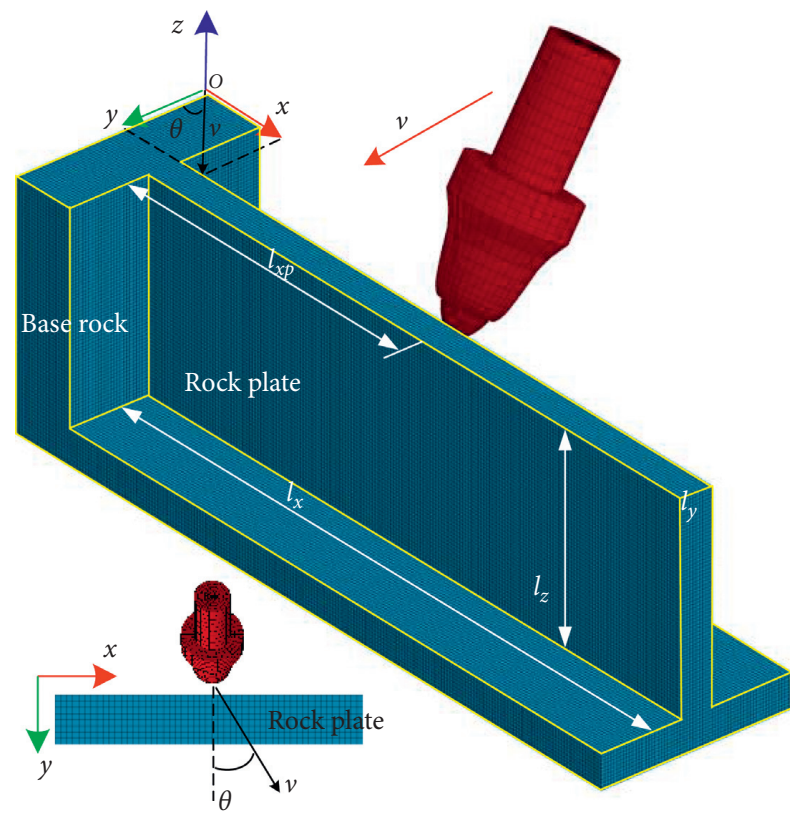

Figure 3: The interaction model between conical pick and rock plate.
JOHNSON_HOLMQUIST_CONCRETE (JHC) [25]. In order to achieve the consequence of rock cracking and fracture morphology, ERODING CONTACT, AUTOMATIC_GENERAL, erosion element failure, and damage constitutive are adopted in the model.

The bottom surface of the base rock is restricted by all degrees of freedom. The direction of conical pick movement is taken as front, and the right surface, front surface, and back surface of base rock are restricted by symmetric constraint. Simultaneously, the NON-REFLECTION boundary condition is assigned to the aforementioned surface. With the above constraints, the base rock can be modeled as an infinity rock. Thereby, the influence of stress wave can be eliminated. As is illustrated in Figure $3, l_{x}, l_{y}$, and $l_{z}$ represent width, thickness, and height, respectively. To research the width and height of rock plate influencing rock cutting performance, the widths are $40 \mathrm{~mm}, 60 \mathrm{~mm}, 80 \mathrm{~mm}$, $120 \mathrm{~mm}, 160 \mathrm{~mm}, 200 \mathrm{~mm}, 300 \mathrm{~mm}, 400 \mathrm{~mm}$, and $500 \mathrm{~mm}$, and the heights are $20 \mathrm{~mm}, 30 \mathrm{~mm}, 40 \mathrm{~mm}, 60 \mathrm{~mm}, 80 \mathrm{~mm}$, $120 \mathrm{~mm}, 160 \mathrm{~mm}$, and $200 \mathrm{~mm}$. The cutting position also has significant influence on rock fracture morphology. $l_{x p} / l_{x}$ is defined as cutting position and modeled as $1 / 8,1 / 4,3 / 8,1 / 2$, $5 / 8,3 / 4$, and $7 / 8$. In xoy coordinate plane, the angle between the moving direction of conical pick and $y$-axis is defined as skew angle, represented by $\theta$, as is shown in Figure 3. When the moving direction component of conical pick in $x$-axis is consistent with the positive direction of $x$-axis, $\theta$ is negative; on the contrary, $\theta$ is positive. In the numerical simulation model, the skew angles are given by $\pm 5^{\circ}, \pm 10^{\circ}, \pm 15^{\circ}, \pm 20^{\circ}$, $\pm 25^{\circ}$, and $\pm 30^{\circ} . \alpha, \beta$, and $\delta$ are tip angle, attack angle, and rake angle as shown in Figure 4 , which are $80^{\circ}, 57^{\circ}$, and $-7^{\circ}$, respectively, in the present paper.

2.3. Mechanical Properties Test. Mechanical properties of rock are necessary for numerical simulation of rock cutting modeling. An analysis of the material parameter employed to model the rock shows that uniaxial compressive strength (UCS), tensile strength $(T)$, modulus of elasticity $(E)$, and density $(D)$ are the most important properties in the numerical simulation. The uniaxial compression test is carried out on the pressure testing machine, presented in Figure 5. The samples are cylinders with $50 \mathrm{~mm}$ diameter and $100 \mathrm{~mm}$ height. Time loading and stress rate loading are widely used compression methods, and in the paper, stress rate loading is employed with $0.5 \mathrm{MPa} / \mathrm{s}$. The broken result of sample in uniaxial compression test is presented in Figure 6 and the stress-strain curve obtained from uniaxial compression test is shown in Figure 7. The elasticity modulus is calculated at $50 \%$ maximum value of UCS. The tensile strength is tested by Brazilian splitting method, with the samples of cylinder with $50 \mathrm{~mm}$ diameter and $50 \mathrm{~mm}$ height. The volume of specimen can be calculated and the weight can be measured by the balance. Further, the density of rock can be acquired from volume divided by weight. All parameters are obtained by averages of three tests. To investigate different rocks influencing rock cutting force, four rocks are collected and tested. The mechanical properties of different rocks are shown in Table 1. 


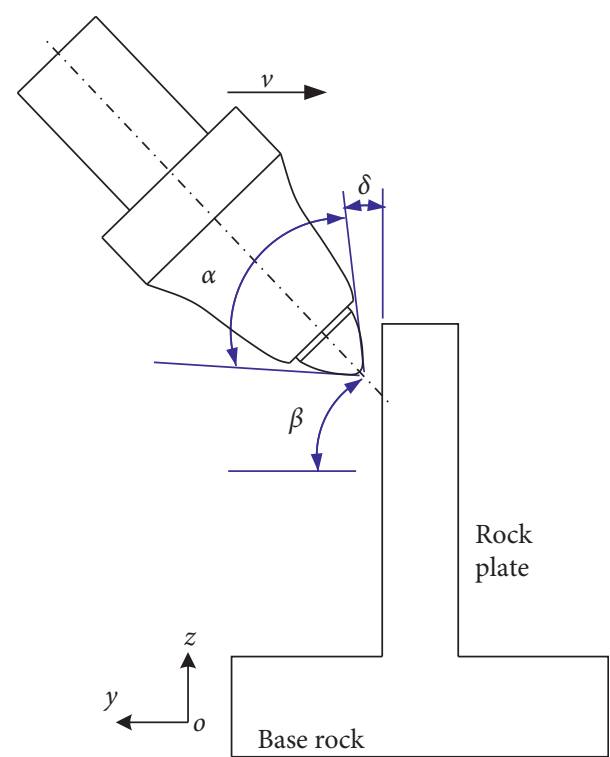

FIgUre 4: Angles related to the conical pick.

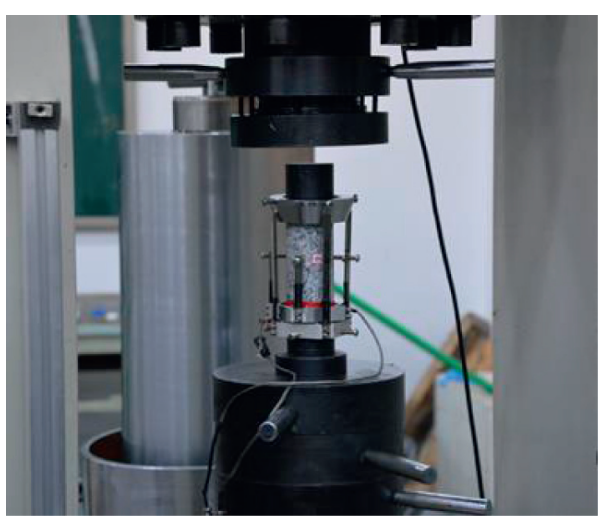

Figure 5: Uniaxial compression test.

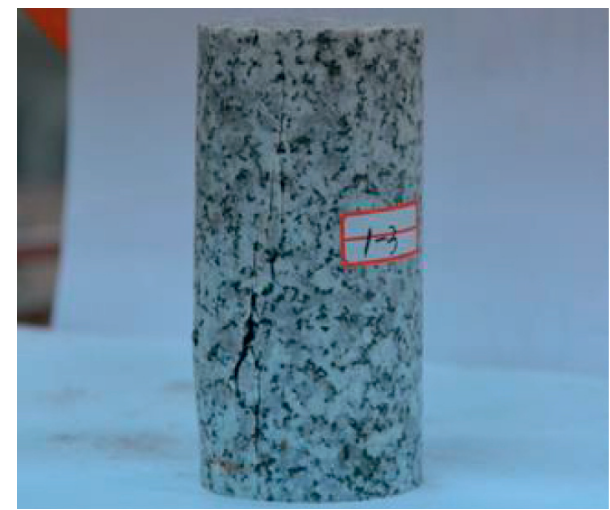

FIGURE 6: Broken result of sample in the uniaxial compression test.

2.4. Rock Cutting Test. In order to verify the correctness and feasibility of the numerical simulation method, the cutting testbed is built as in Figure 8. The testbed mainly consists of a hydraulic power system, rock cutting assembly, and signal acquisition system. Besides, the hydraulic power system consists of a pumping station, hydraulic system control unit,

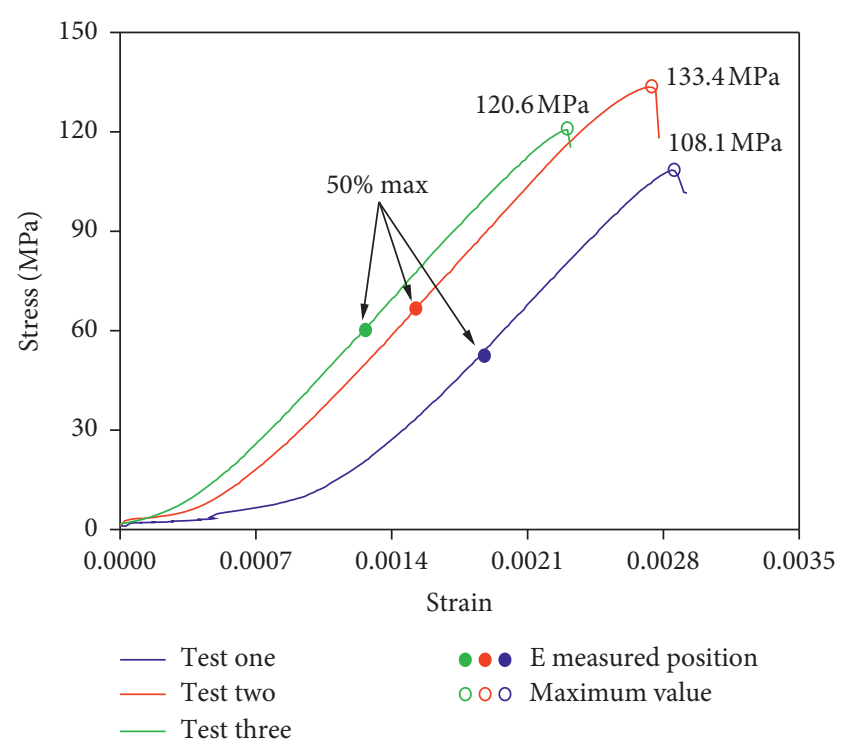

FIGURE 7: Stress-strain curve obtained from the uniaxial compression test.

TABle 1: Mechanical properties of rocks.

\begin{tabular}{lcccc}
\hline Rock name & UCS $(\mathrm{MPa})$ & $\mathrm{BTS}(\mathrm{MPa})$ & $E(\mathrm{GPa})$ & $\gamma\left(\mathrm{kg} / \mathrm{m}^{3}\right)$ \\
\hline Granite & 120.7 & 12.1 & 45.5 & 2732 \\
Marble & 43.8 & 5.3 & 52.9 & 2670 \\
Sandstone-1 & 86.4 & 7.9 & 54.5 & 2683 \\
Sandstone-2 & 139.1 & 10.6 & 58.3 & 2716 \\
\hline
\end{tabular}

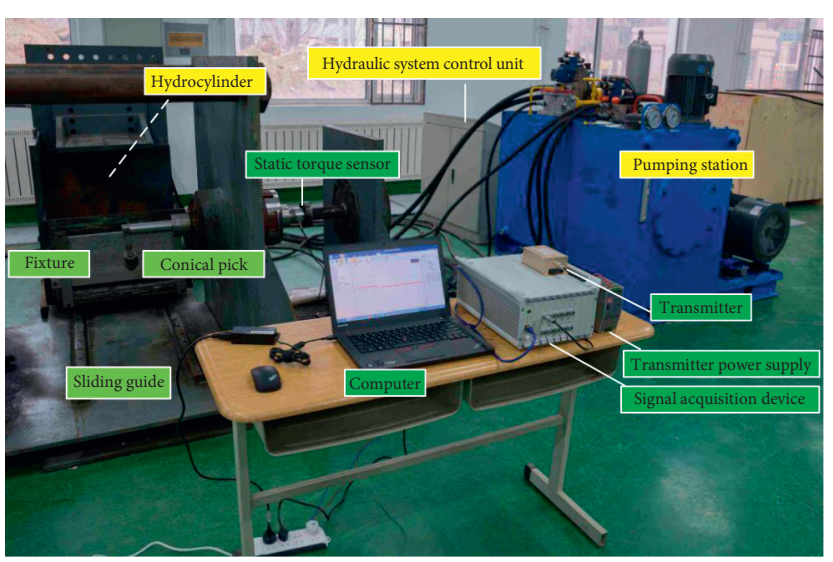

Hydraulic power system

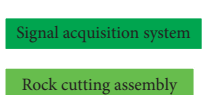

FIgURE 8: Rock plate cutting testbed.

and hydrocylinder. The hydrocylinder is arranged on the back of the fixture. The cutting assembly consists of a fixture, conical pick, and sliding guides. The signal acquisition system consists of static torque sensor, transmitter, signal acquisition device, and computer. The main functions of the hydraulic power system, the cutting 
assembly, and signal acquisition system are to push the fixture move on the guide rail, cut rock, and obtain voltage signal, respectively. The conical pick is fixed and rock plate moves with the expansion of the hydraulic cylinder, and then the rock plate is cut and cutting force is generated. The conical pick is connected to the static torque sensor through the coupling so that the voltage signal can be generated by the static torque sensor. The static torque sensor ranges within $0 \sim \pm 3000 \mathrm{Nm}$. The voltage signal in $\mathrm{mV}$ can be generated by static torque sensor under the action of cutting force and amplified by transmitter to $\mathrm{V}$ unit. The input signal and output signal of transmitter range within $0 \sim \pm 5 \mathrm{mV}$ and $0 \sim \pm 2.5 \mathrm{~V}$, respectively. The voltage signal emitted by transmitter is processed by signal acquisition device and displayed on the computer. Thus, the cutting force can be obtained by calculation. In the paper, the sampling frequency of signal acquisition device is $10 \mathrm{kHz}$.

2.5. Experimental Verification. Numerical simulation is a common research method with high efficiency and low cost; however, its correctness needs to be verified. In the paper, numerical simulation and experiment are carried out at the same cutting parameters and physical parameters of rock. The numerical and experimental cutting results of rock plate with $l_{x}, l_{y}$, and $l_{z}$ of $500 \mathrm{~mm}, 20 \mathrm{~mm}$, and $200 \mathrm{~mm}$ are presented in Figures 9 and 10, respectively. In the experiment, fixed boundary is adopted to replace the base bock in the simulation. Comparison shows clearly that the rock plate fracture morphology obtained from numerical simulation and experiment is very similar. The fracture positions presented in Figure 9 and in Figure 10 are almost the same. The bottom fixed boundary of rock plate is broken, with the main crack generated in the middle of rock plate. However, the rock fracture in the experimental conditions is not as regular as the numerical simulation because natural rock is inhomogeneous. Compared with the experimental result, the cutting position in numerical approach is broken, but it does not affect the integral fracture morphology of rock plate.

The cutting forces obtained from experiment and numerical simulation have the same characteristics, presented in Figure 11. With cutting distance increased, the cutting force increases slowly at the beginning and then decreases rapidly to zero. In the process of descending cutting force, both numerical and experimental results have a fluctuation. The maximum cutting forces are basically the same, with $1.9 \mathrm{kN}$ and $2.1 \mathrm{kN}$ acquired in the experimental and numerical approaches, respectively. The numerical simulation results show that the cutting force fluctuates during the rising process, mainly due to the rock element failure and deletion in the numerical cutting process. Another difference is that the cutting process of the experiment is longer than numerical simulation, because the conical pick generates slight deformation with the increased cutting force; however, the conical pick is rigid and assigned by the constant velocity in numerical simulation, so no deformation will happen. By analyzing cutting force and fracture

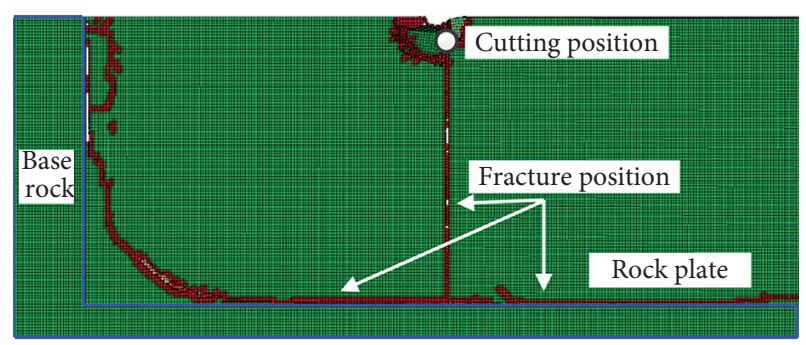

Figure 9: Numerical simulation cutting result.

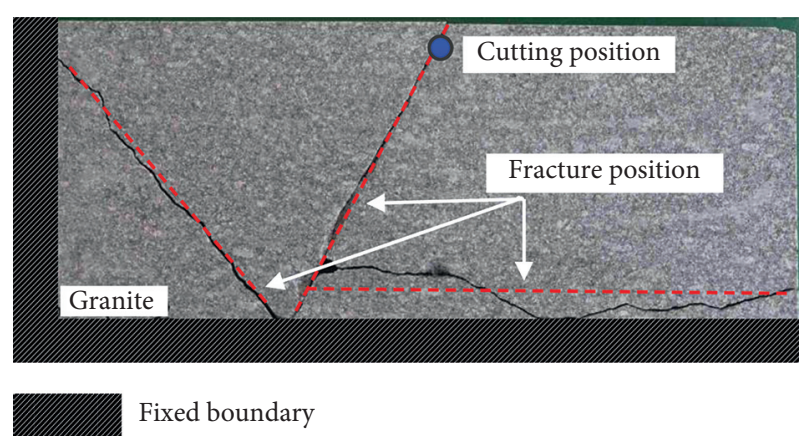

Figure 10: Experimental cutting results.

morphology, it can be concluded that the numerical simulation adopted in the paper is credible and feasible.

\section{Results and Discussion}

The cutting results of granite at thickness of $20 \mathrm{~mm}$, height of $160 \mathrm{~mm}$, and widths of $60 \mathrm{~mm}, 120 \mathrm{~mm}, 200 \mathrm{~mm}$, and $400 \mathrm{~mm}$ are illustrated in Figure 12. It can be seen that, at the width of $60 \mathrm{~mm}$, the cutting result is different from others in that the main crack does not penetrate the midline of rock plate. At the widths of $120 \mathrm{~mm}, 200 \mathrm{~mm}$, and $400 \mathrm{~mm}$, the main cracks divide the rock plates into left and right parts. According to the fracture region, the rock plates with widths of $200 \mathrm{~mm}$ and $400 \mathrm{~mm}$ are basically integrally broken. But at widths of $60 \mathrm{~mm}$ and $120 \mathrm{~mm}$, part of the rock plates remains on the base rock, occupying about $1 / 4$ of the whole rock plate. It can be concluded that the larger width is more beneficial to rock plate cutting. On the right side of the main crack, the rock plate is broken along the bottom, forming larger fragments, which is the same with the test result.

At lower width, the rock plate is unable to break fully due to the bending moment generated by great cutting force changes from top to bottom on the left boundary. After the corner breaks, the rock plate generates greater internal force under higher cutting force, and the crack propagates to the internal of the rock plate. The rock plate integral breaks on the right side of the main crack, because the rock plate on this side becomes a rock plate with three sides free and one side fixed after the generation of main crack. In the height direction, the maximum bending moment is generated at the fixed boundary, where the rock plate breaks. Compared with [24], it can be seen that the fracture morphology is different obviously with the rock plate with three sides fixed and two sides fixed. 


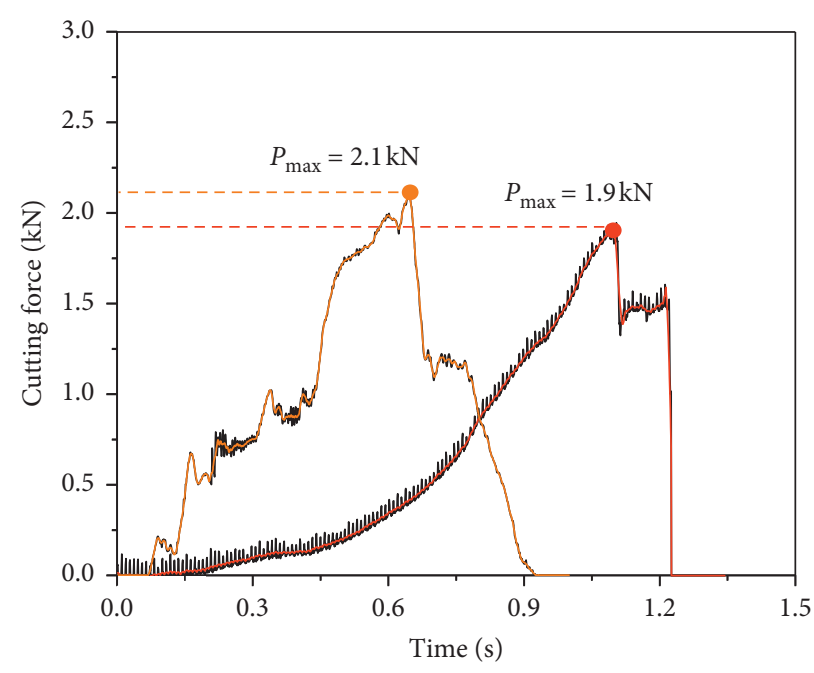

- Numerical result

- Experimental result

FIGURE 11: Numerical and experimental cutting force.

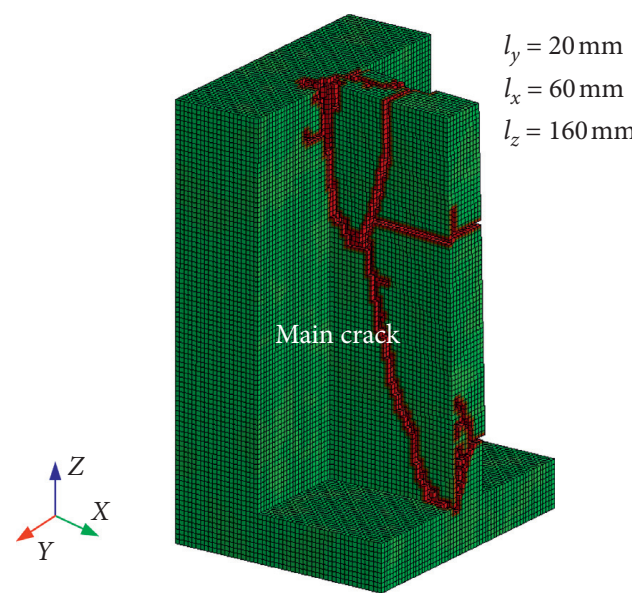

(a)

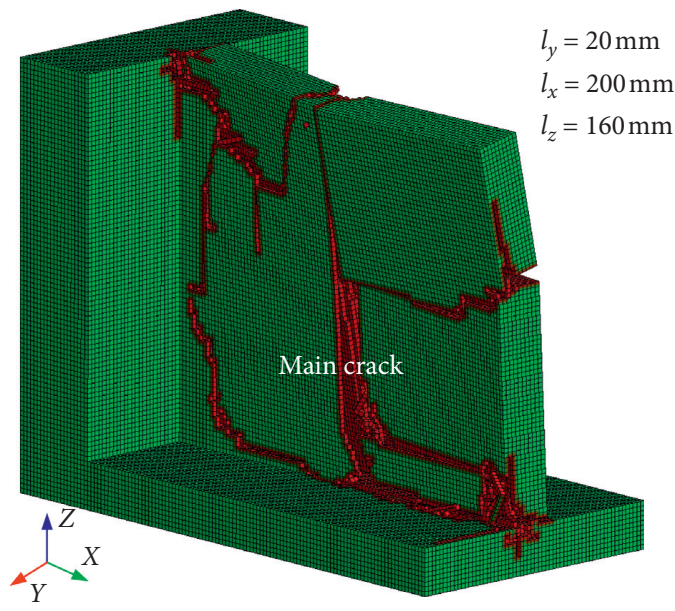

(c)

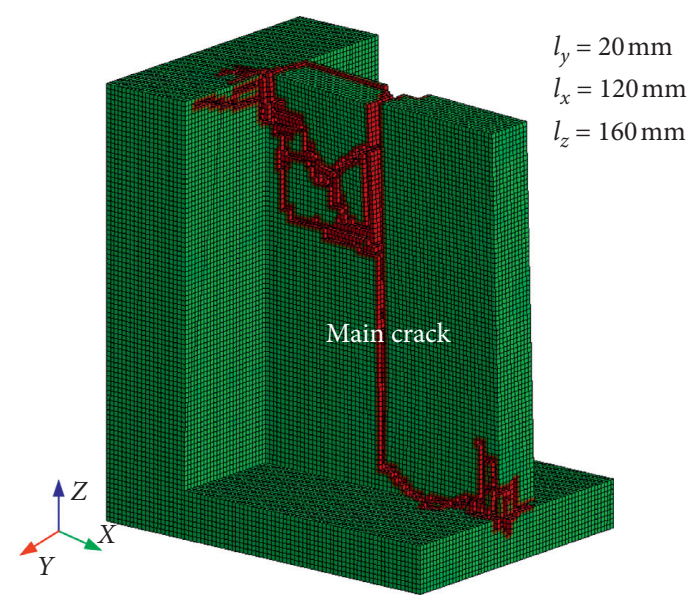

(b)

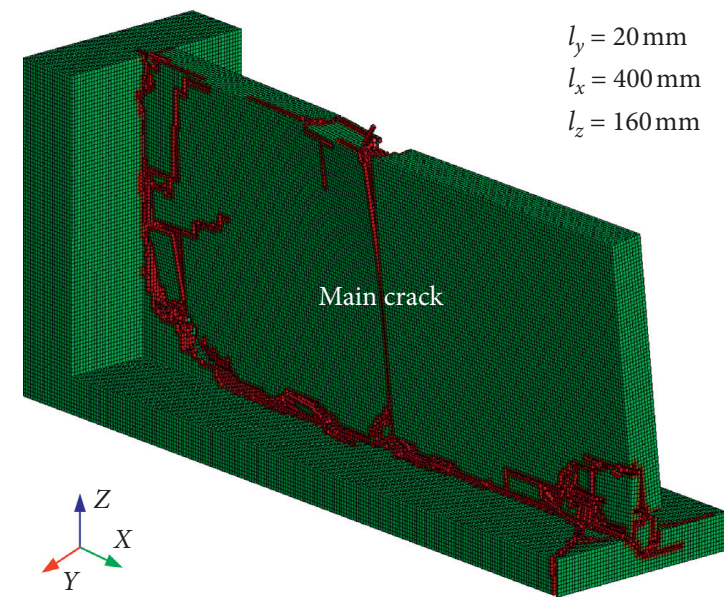

(d)

Figure 12: Numerical results of rock plates at different widths: (a) $60 \mathrm{~mm}$, (b) $120 \mathrm{~mm}$, (c) $200 \mathrm{~mm}$, and (d) $400 \mathrm{~mm}$. 

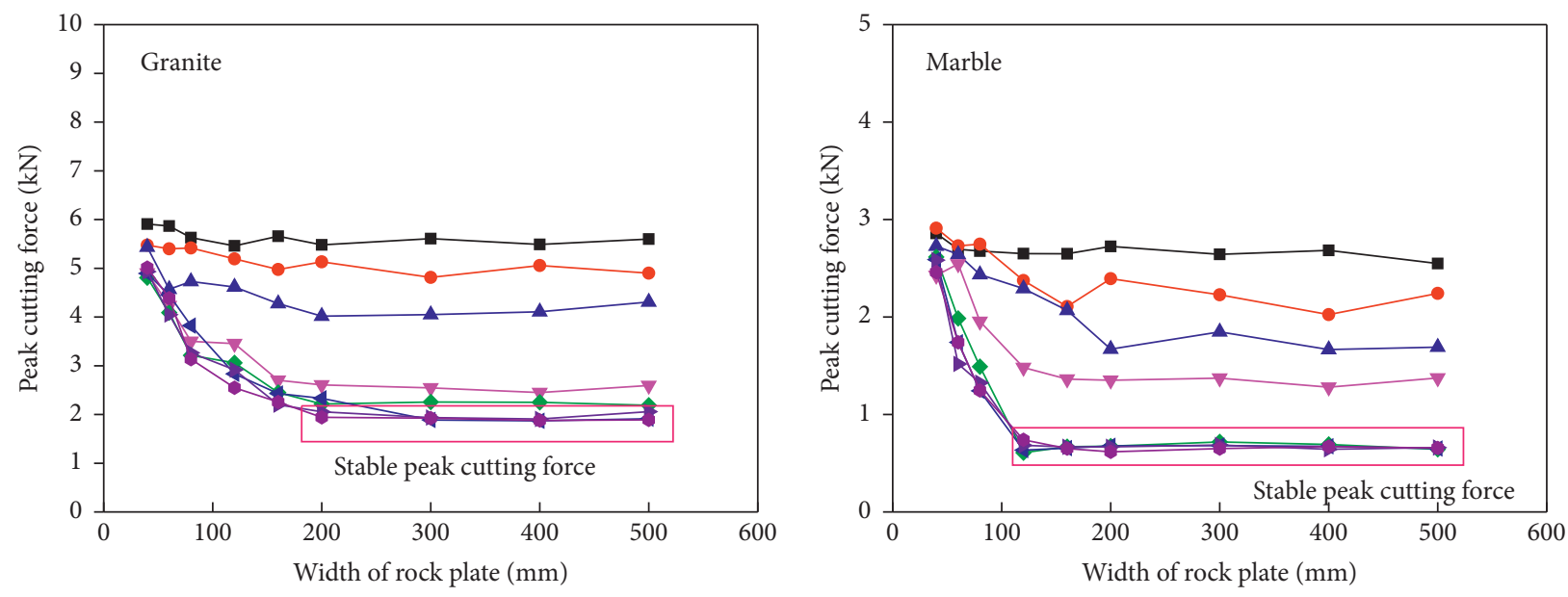

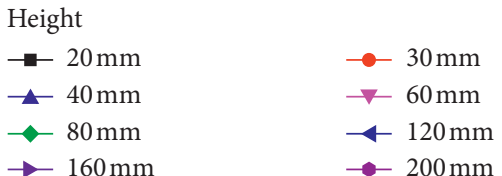

(a)

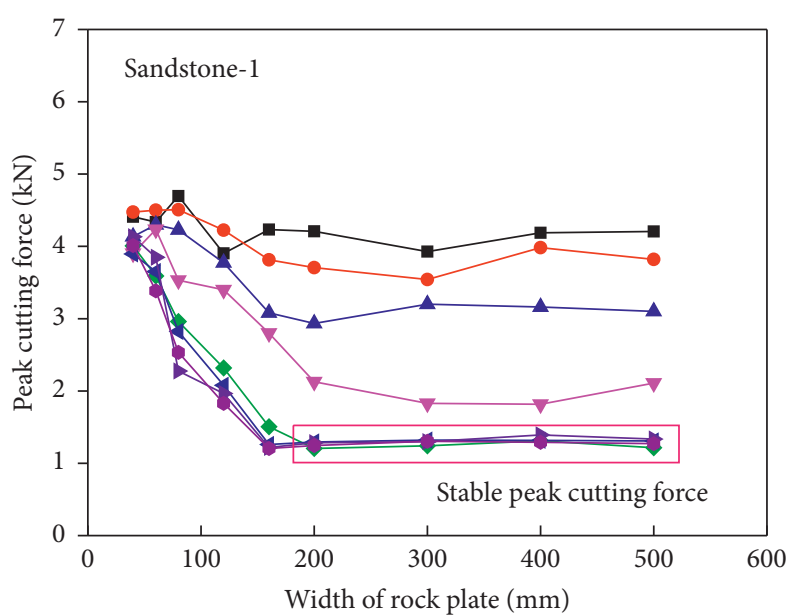

Height

$$
\begin{aligned}
& \rightarrow-20 \mathrm{~mm} \\
& \rightarrow-40 \mathrm{~mm} \\
& \rightarrow-80 \mathrm{~mm} \\
& \rightarrow-160 \mathrm{~mm}
\end{aligned}
$$$$
\begin{aligned}
& \longrightarrow 30 \mathrm{~mm} \\
& \neg 60 \mathrm{~mm} \\
& \leftarrow 120 \mathrm{~mm} \\
& -200 \mathrm{~mm}
\end{aligned}
$$

(c)

FIGURE 13: Variation of the PCF with heights of rock plates: (a) granite, (b) marble, (c) sandstone-1, and (d) sandstone-2.
Height

$$
\begin{aligned}
& \rightarrow-20 \mathrm{~mm} \\
& -40 \mathrm{~mm} \\
& \longrightarrow-80 \mathrm{~mm} \\
& \rightarrow 160 \mathrm{~mm}
\end{aligned}
$$

(b)
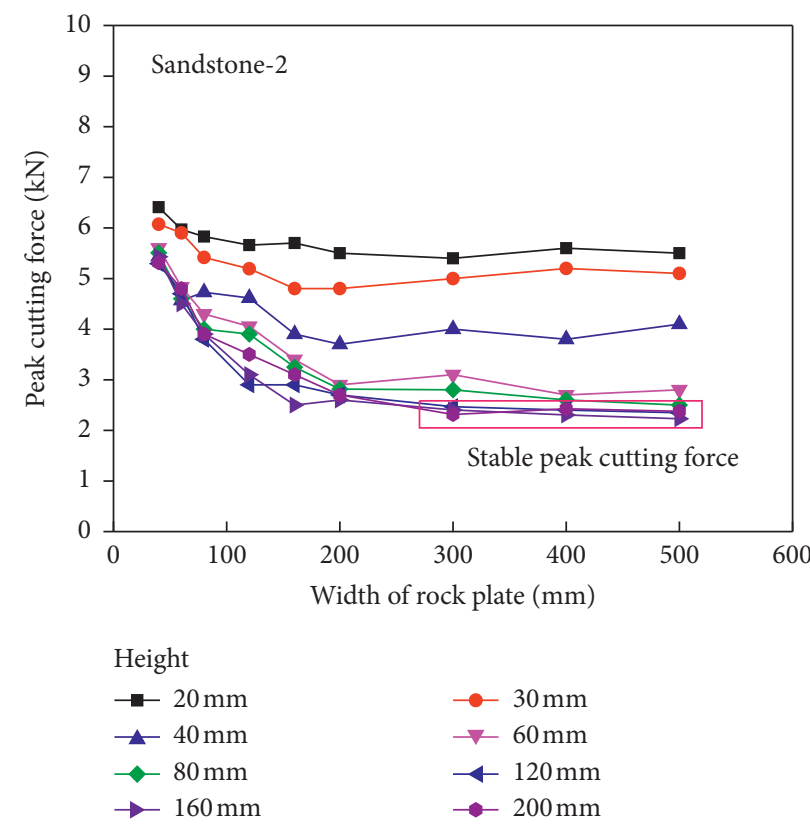

(d)
The variation of peak cutting force (PCF) with different heights of four different rocks is illustrated in Figure 13. For rocks with different mechanical properties, the PCF variation has the same regularity. At the lower height of rock plate, the changed amplitude of the peak cutting force is obsolete. On the contrary, at the higher height of the rock plate, PCF varies obviously with width. On the whole, the PCF decreases obviously with the increasing width, then decreases slightly with increasing width, and then keeps stable.
For rock plate with certain thickness, the minimum PCF is defined as stable peak cutting force (SPCF). The significance of defining the SPCF is to find the rock plate size corresponding to the minimum PCF. As is demonstrated in Figure 14, with regard to the rock plate with two sides fixed and two sides free, different SPCFs are obtained from rock plate cutting with different mechanical properties, and the corresponding sizes of rock plates are also different. Therefore, from the perspectives of PCF and rock fracture area, rock plate of higher width is more conducive to rock 


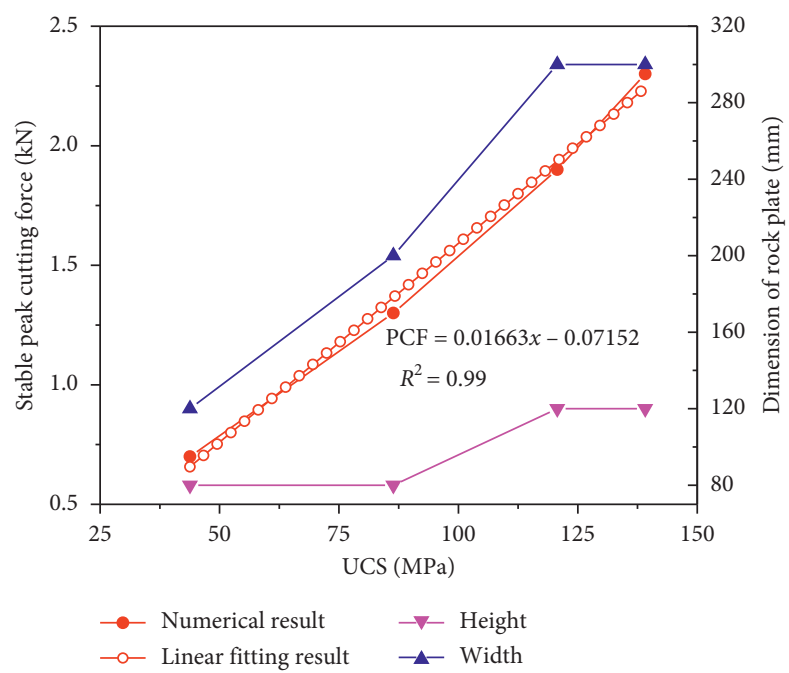

FIGURE 14: SPCF and rock dimension variation with UCS of rock.

TABle 2: Minimum dimensions of rock plates corresponding to SPCF.

\begin{tabular}{lcccc}
\hline Rock plate & Marble & Granite & Sandstone- & Sandstone-2 \\
\hline Height $(\mathrm{mm})$ & 80 & 120 & 80 & 120 \\
Width $(\mathrm{mm})$ & 120 & 300 & 200 & 300 \\
SPCF $(\mathrm{kN})$ & 0.7 & 1.9 & 1.3 & 2.3 \\
\hline
\end{tabular}

cutting. The SPCF and the corresponding minimum dimension of rock plate with different rock properties are illustrated in Table 2. The SPCFs of marble, granite, sandstone-1, and sandstone- 2 at thickness of $20 \mathrm{~mm}$ are $0.7 \mathrm{kN}$, $1.9 \mathrm{kN}, 1.3 \mathrm{kN}$, and $2.3 \mathrm{kN}$, respectively. The SPCF variation with UCS is presented in Figure 14. The SPCF increases steadily with the increasing UCS of rock plate. The UCS and SPCF have linear positive relationship according to linear fitting equation. $R^{2}$ equal to 0.99 indicates that the relationship is strong. According to Table 2 and Figure 14, the minimum dimension of rock plate corresponding to the SPCF also tends to increase with the increasing UCS. However, only when UCS increases to a certain amount, the corresponding minimum rock plate dimension will increase. In detail, comparisons of marble, granite, and sandstone-1 show that the minimum dimension of rock plate corresponding to SPCF increases obviously. However, when comparison is made between granite and sandstone-2, the minimum dimension of rock plate is the same, because the difference of compressive strength between granite and sandstone- 2 is relatively small.

The fitting curves between PCF and height of rock plate at $500 \mathrm{~mm}$ in width and $20 \mathrm{~mm}$ in thickness are presented in Figure 15. The regression analysis results are illustrated in Table 3. From the fitting results, it can be seen that exponential negative correlation exists between PCF and width or rock plate for rocks with different mechanical properties. All of the $R^{2}$ values obtained from regression analysis are greater than 0.97 , indicating that the relationship between PCF and width of rock plate is strong. The statistical confidence level in the paper is 0.95 , which requires the $P$ value to be less than 0.05 [26]. As can be seen from Table 3 , all the $P$ values are less

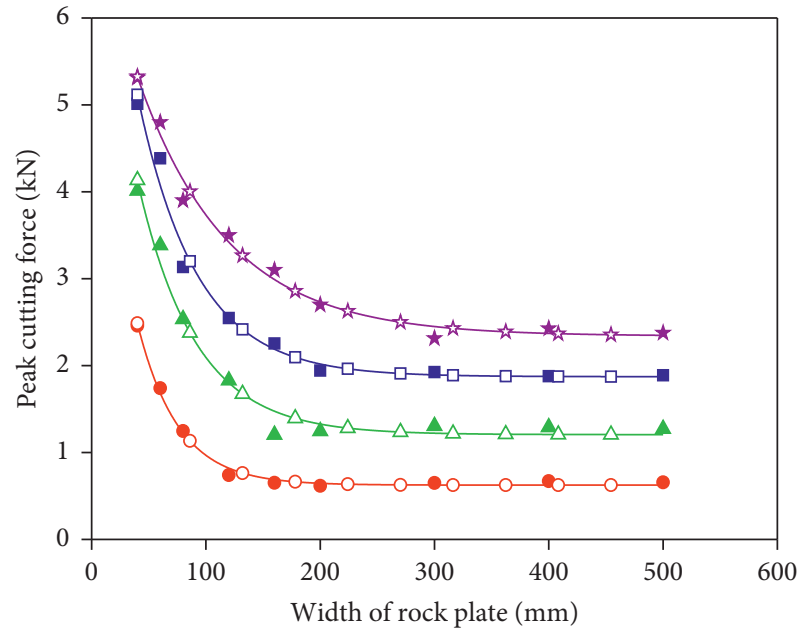

$\begin{array}{ll}\text { Numerical result } & \text { Fitting result } \\ \star \text { Sandstone-2 } & -\longleftarrow \text { Sandstone-2 } \\ \text { - Granite } & -\square \text { Granite } \\ \triangle \text { Sandstone-1 } & -\triangle \text { Sandstone-1 } \\ \text { - Marble } & -\circ \text { Marble }\end{array}$

Figure 15: Regression analysis curves between height and PCF.

than 1e-7, indicating that the regression analysis is believable.

The cutting results of rock plates with $20 \mathrm{~mm}$ in thickness and $40 \mathrm{~mm}$ in width at heights of $20 \mathrm{~mm}, 40 \mathrm{~mm}$, $80 \mathrm{~mm}$, and $160 \mathrm{~mm}$ are shown in Figure 16 and Figure 12(d). At the height of $20 \mathrm{~mm}$ as presented in Figure 16(a), the middle area of rock plate is broken. By 
TABLE 3: Regression analysis results between height and PCF.

\begin{tabular}{lccccc}
\hline Rock & \multicolumn{1}{c}{ Fitting equation } & $R^{2}$ & $F$ value & $P$ value & Relationship \\
\hline Marble & PCF $=0.62519+5.75481 \exp (-0.0282 \mathrm{x})$ & 0.99 & 1604 & $7 e-9$ & Exponent-negative \\
Sandstone-1 & PCF $=1.20563+6.48736 \exp (-0.01988 \mathrm{x})$ & 0.98 & 570 & $1 e-7$ & Exponent-negative \\
Granite & $\mathrm{PCF}=1.87245+7.04803 \exp (-0.01939 \mathrm{x})$ & 0.98 & 924 & $3 e-8$ & Exponent-negative \\
Sandstone-2 & $\mathrm{PCF}=2.33979+4.96324 \exp (-0.0127 \mathrm{x})$ & 0.98 & 1897 & $4 e-9$ & Exponent-negative \\
\hline
\end{tabular}

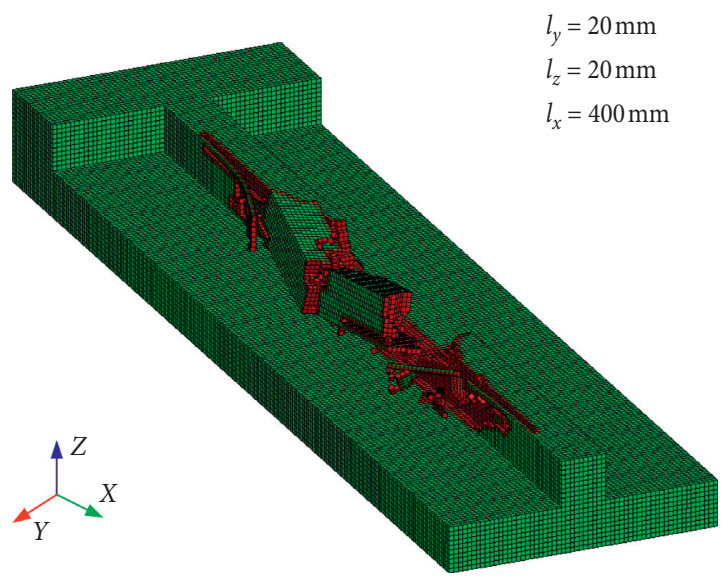

(a)

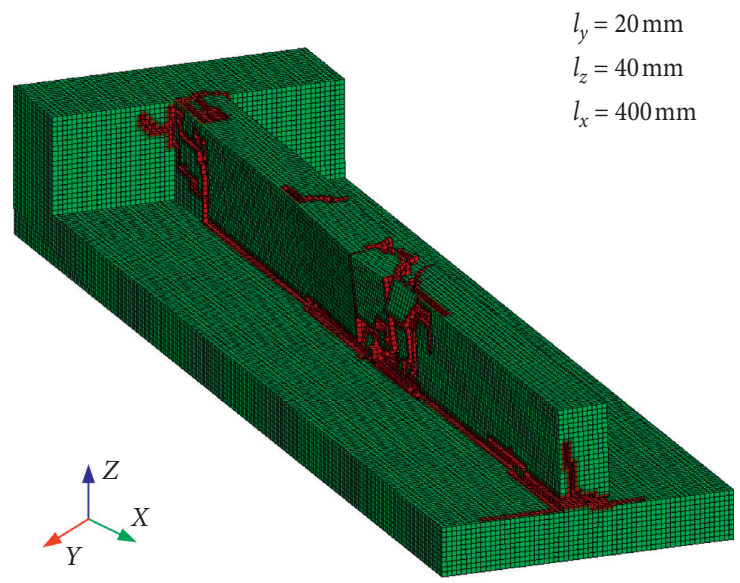

(b)

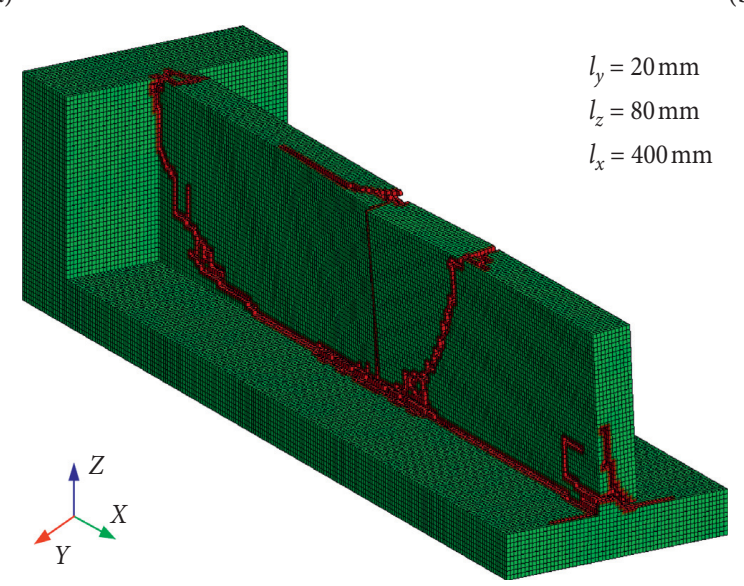

(c)

FIGURE 16: The fracture morphology with different heights: (a) $20 \mathrm{~mm}$, (b) $40 \mathrm{~mm}$, and (c) $80 \mathrm{~mm}$.

comparing with Figure 16(b), Figure 16(c), and Figure 12(d), the rock fragments formed are smaller in dimension but larger in quantity. When the height increases to $40 \mathrm{~mm}$, the rock plate generates integral fracture. At the same time, a small quantity of fragments still exists. At the height of $80 \mathrm{~mm}$, the rock plate breaks integrally with no fragment generated, the same with height of $160 \mathrm{~mm}$ as presented in Figure 12(d). Therefore, at the higher height of the rock plate, the rock fracture morphology is similar.

The PCF variation with height for different rocks is shown in Figure 17. For a certain height and thickness, the larger the width, the larger the variation of PCF. At the width of $40 \mathrm{~mm}$, the variation of PCF with height is not significant. However, when the width of rock plate increases to $60 \mathrm{~mm}$, the PCF shows a significant change with the height of rock plate. The PCF decreases with the increasing height, until it reaches SPCF and the cutting force no longer reduces. The SPCF obtained from Figure 17 is the same with Table 2. The rock plate breaks from the bottom at different heights. The bending moment is in direct proportion to cutting force and the distance between cutting position and rock plate bottom. Therefore, in order to obtain the same bending moment at the bottom fixed boundary, lower height of rock plate requires higher cutting force. As a result, higher height of rock plate, beneficial to reduce the PCF, should be obtained in the rock slitting process by the saw blade.

The regression analysis curve is presented in Figure 18 at $500 \mathrm{~mm}$ in width and $20 \mathrm{~mm}$ in thickness for different rocks, and the regression results are illustrated in Table 4. The exponent-negative relationship exists between PCF and height of rock plate. The $R^{2}$ values are all more than 0.95 , indicating that the correlation is strong. The $P$ values are all 

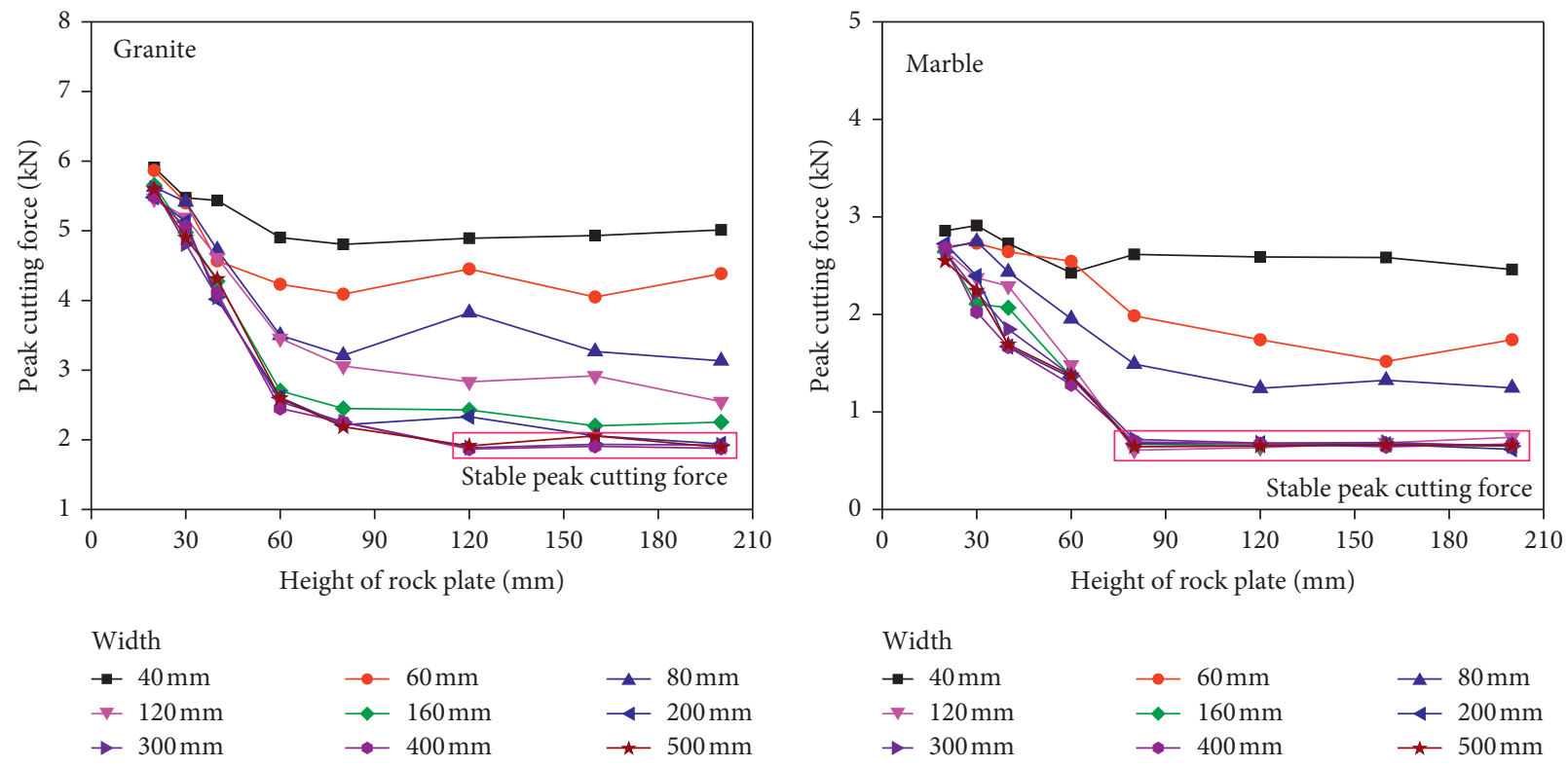

(a)

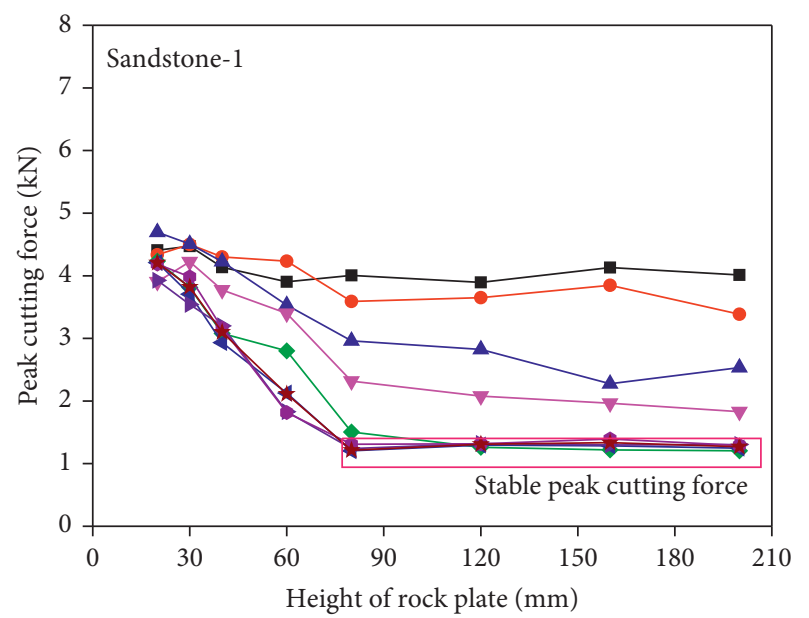

Width

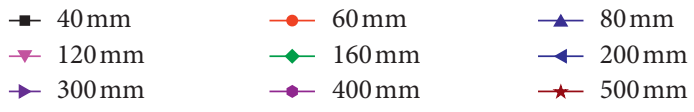

(b)

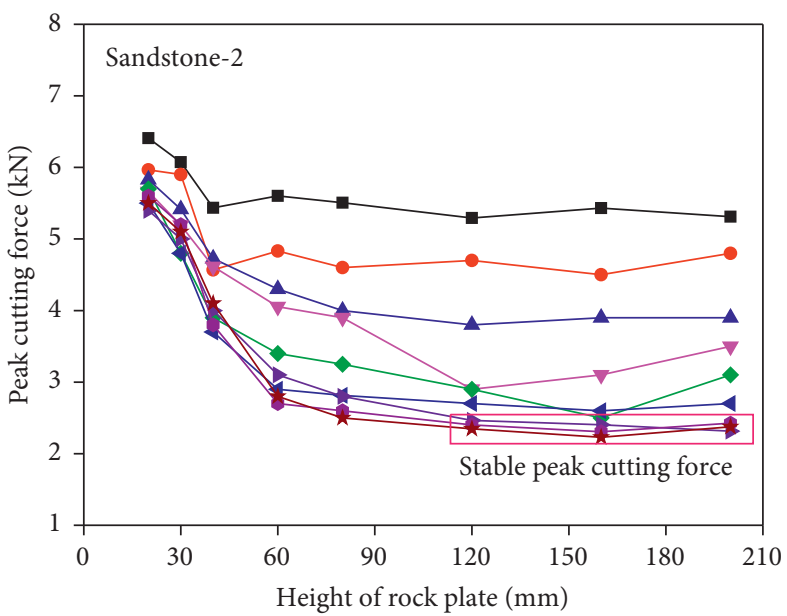

Width

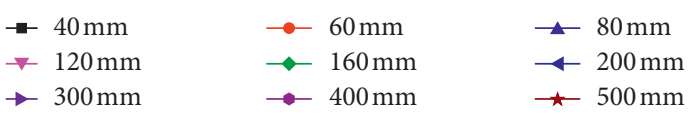

(c)

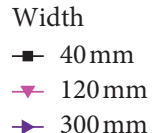

$\rightarrow 300 \mathrm{~mm}$

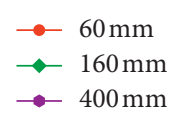

(d)

FIgURE 17: The variation of PCF with height for different rocks: (a) granite, (b) marble, (c) sandstone-1, and (d) sandstone-2.

less than $1 e-5$, proving that the relationship between PCF and height of rock plate is significant in statistics.

The cutting results of rock plates of granite at $500 \mathrm{~mm}$ in width, $200 \mathrm{~mm}$ in height, and $20 \mathrm{~mm}$ in thickness with skew angles of $-5^{\circ},-15^{\circ}, 30^{\circ}$, and $-30^{\circ}$ are illustrated in Figure 19. At the skew angles of $-5^{\circ}$ and $-15^{\circ}$, the cutting results are almost the same, with the main crack generated at the middle of rock plate and the position of fixed boundary. At the skew angles of $30^{\circ}$ and $-30^{\circ}$, rock plate fractures are with randomness, with obviously different frature morphology from that of lower skew angle. In the cutting process, the quantity of cracks and rock fragments increase obviously, but the dimension of fragmentations significantly reduces.
At the skew angle of $-30^{\circ}$, the cutting force is mainly born on the left part of rock plate, leading to more cracks generated here. Furthermore, the fracture position is no longer located at the fixed boundary, resulting in the fracture area of right part decreased.

As can be seen from Figure 20, at the positive and negative skew angles, the maximum PCFs are obtained at skew angles of $10^{\circ}$ and $-10^{\circ}$, respectively. It shows that the PCF increases and decreases with the increasing skew angle of conical pick. The variation of PCF is symmetrical with $0^{\circ}$ as symmetrical center.

The cutting results at the cutting positions of $1 / 8$ and $7 / 8$ are presented in Figure 21. At the cutting position of $1 / 8$, it 


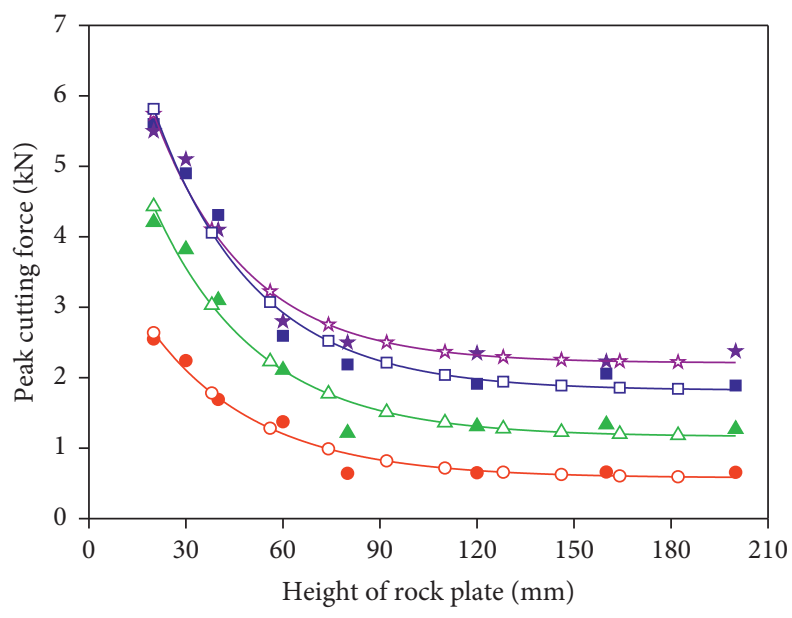

$\begin{array}{ll}\text { Numerical result } & \text { Fitting result } \\ \star \text { Sandstone-2 } & -\leftarrow \text { Sandstone-2 } \\ \text { - Granite } & -\square-\text { Granite } \\ \Delta \text { Sandstone-1 } & -\triangle-\text { Sandstone-1 } \\ \text { - Marble } & -\circ \text { - Marble }\end{array}$

FIGURE 18: Regression analysis curves between height and PCF.

TABLE 4: Regression analysis results between height and PCF.

\begin{tabular}{llccrr}
\hline Rock & \multicolumn{1}{c}{ Fitting equation } & $R^{2}$ & $F$ value & $P$ value & Relationship \\
\hline Marble & PCF $=0.5766+3.73836 \exp (-0.02974 \mathrm{x})$ & 0.99 & 208 & $1 e-5$ & Exponent-negative \\
Sandstone-1 & PCF $=1.16195+6.08036 \exp (-0.03104 \mathrm{x})$ & 0.95 & 227 & $1 e-5$ & Exponent-negative \\
Granite & $\mathrm{PCF}=1.81897+7.60139 \exp (-0.03216 \mathrm{x})$ & 0.96 & 374 & $4 e-6$ & Exponent-negative \\
Sandstone-2 & $\mathrm{PCF}=2.20864+7.06199 \exp (-0.03459 \mathrm{x})$ & 0.96 & 472 & $2 e-6$ & Exponent-negative \\
\hline
\end{tabular}

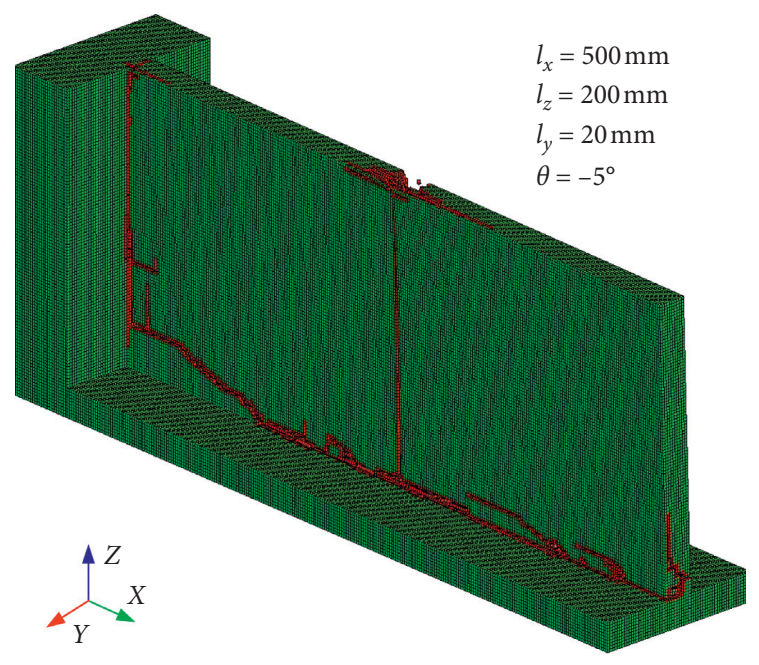

(a)

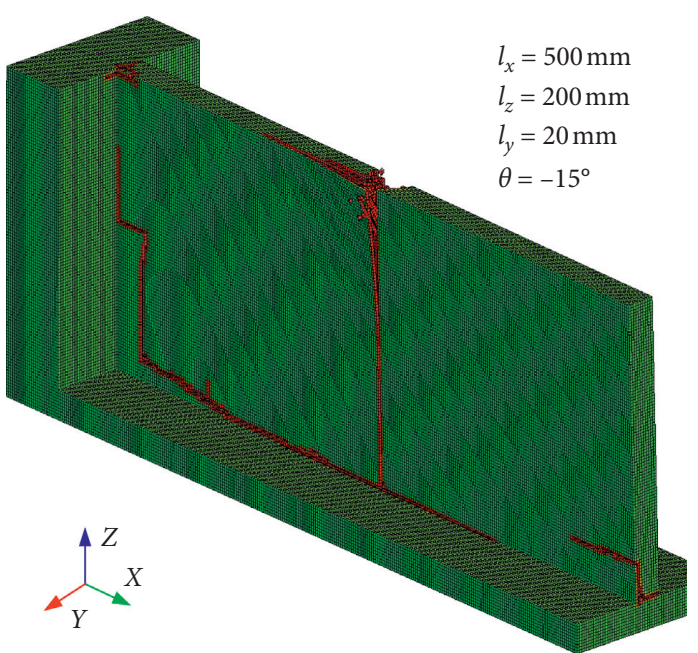

(b)

Figure 19: Continued. 


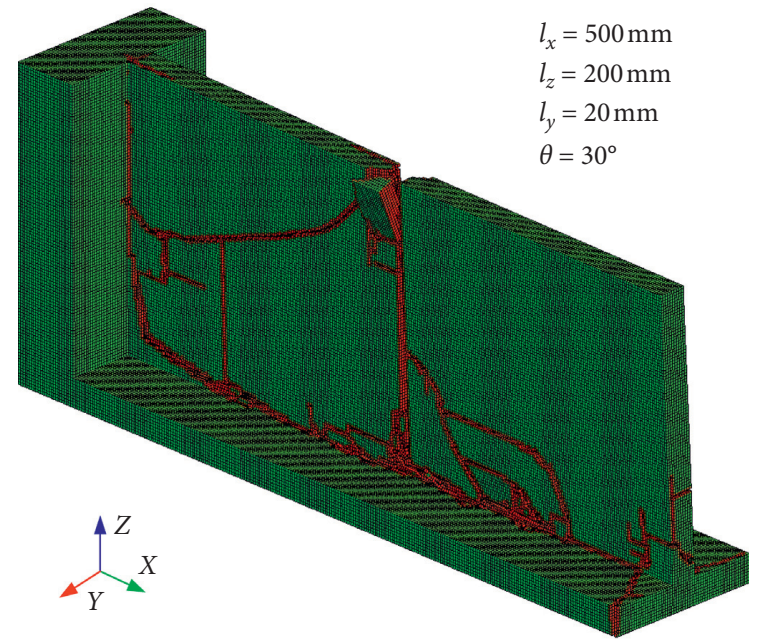

(c)

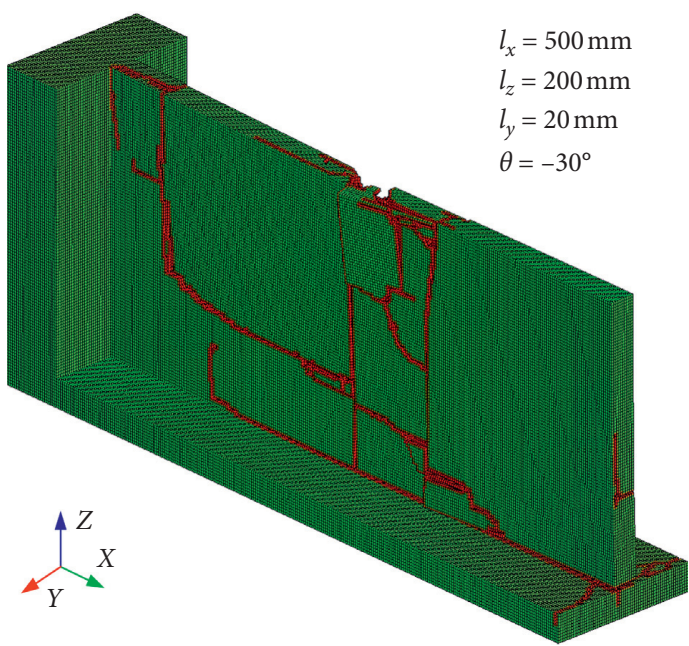

(d)

FIgURE 19: Cutting results with different skew angles: (a) $-5^{\circ}$, (b) $-15^{\circ}$, (c) $30^{\circ}$, and (d) $-30^{\circ}$.

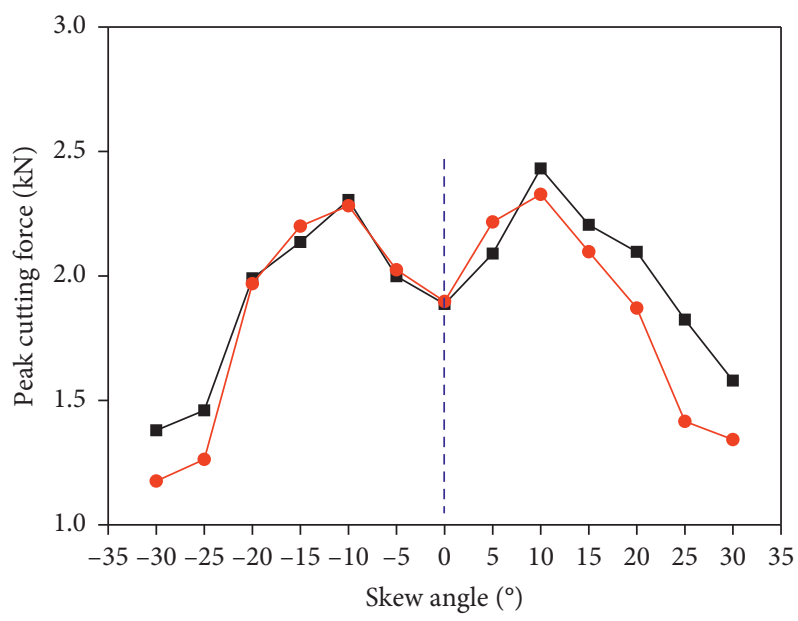

Width Height

$\rightarrow-400 \mathrm{~mm} 160 \mathrm{~mm}$

$\rightarrow 500 \mathrm{~mm} 200 \mathrm{~mm}$

Figure 20: Variation in PCF with skew angle.

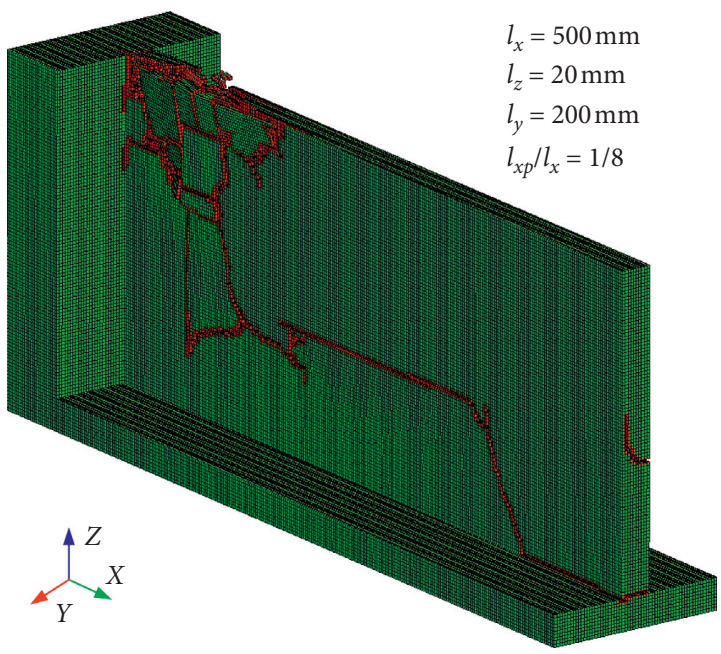

(a)

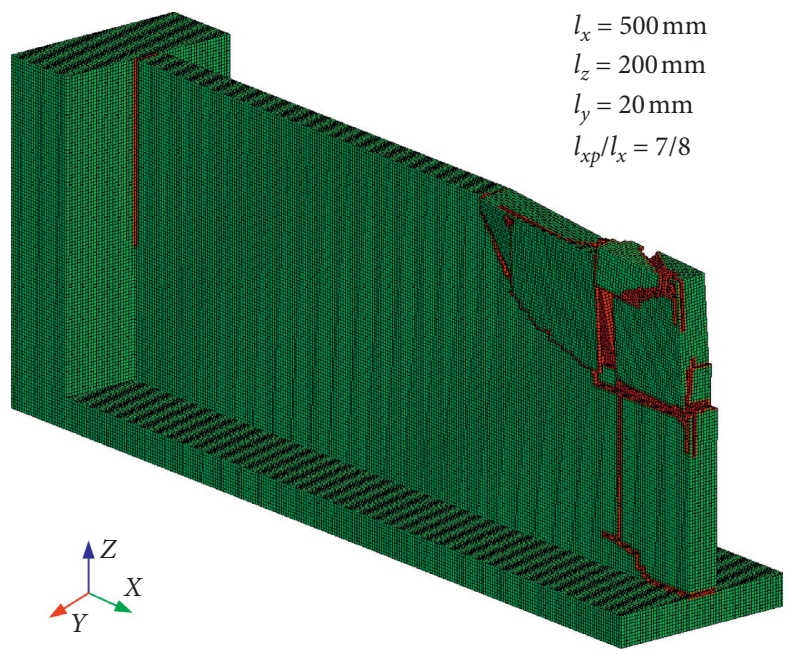

(b)

FIGURE 21: Cutting results of granite with different cutting positions: (a) $l x p / l x=1 / 8$ and (b) $l x p / l x=7 / 8$. 


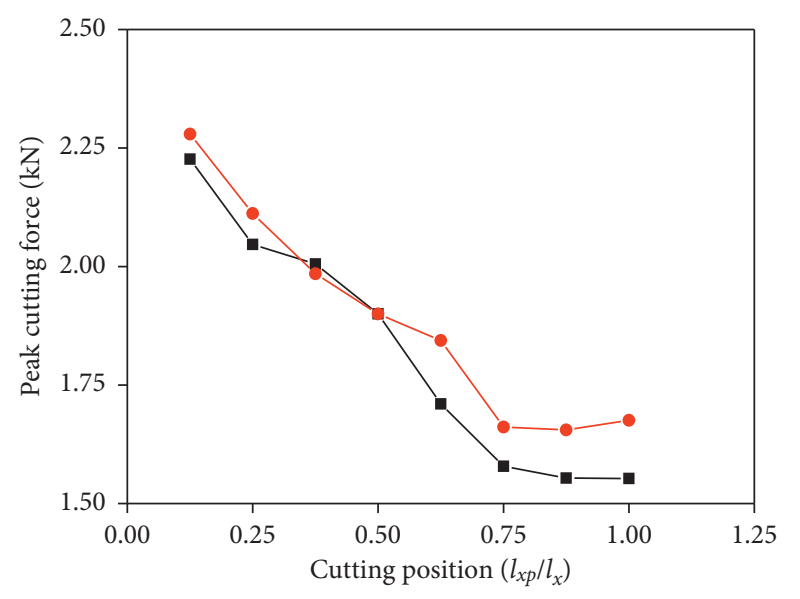

Width Height

$\rightarrow-500 \mathrm{~mm}, 200 \mathrm{~mm}$

$\longrightarrow 400 \mathrm{~mm}, 160 \mathrm{~mm}$

FIGURE 22: Variation of PCF with cutting position.

can be seen that the rock plate is seriously damaged at the cutting position. Meanwhile, fractures also occur in other areas of the rock plate. However, part of the rock plate remains on the base rock. At the cutting position of $7 / 8$, the rock plate is also fractured at the cutting position. The interface between rock plate and base rock is not broken, although cracks occur. Therefore, for the rock plate with two sides fixed and two sides free, the cutting position should not be too far or too close to the constraint side.

The variation of PCF with cutting position is presented in Figure 22. At the cutting positions of $l_{x p} / l_{x}$ within $1 / 8$ and $3 / 4$, the PCF decreases with the increasing cutting position. At the cutting positions within $3 / 4$ and 1 , the cutting force remains stable. For the rock plates with $500 \mathrm{~mm}$ in width and $400 \mathrm{~mm}$ in width, the differences between maximum peak cutting and minimum PCF are all $0.6 \mathrm{kN}$. It indicates that although the peak cutting changes with cutting position, the amplitude of variation is small.

\section{Conclusion}

A hard rock cutting method is proposed based on increased free surface. To research the cutting force and fracture morphology in the course of rock plate cutting, numerical simulation is carried out by LS-DYNA. The mechanical properties of rock are tested and numerical simulation method is validated in an experimental approach:

(1) Compared with the experimental method, the numerical simulation method employed in the study is reliable and credible. Fracture morphology and cutting force of rock plate cutting can be effectively obtained by the simulation model established in the paper.

(2) The fracture morphology obtained from rock cutting process varies obviously with width and height of rock plate, as well as skew angle and cutting position of conical pick. More cracks and fragments are obtained at the lower width and height of rock plate, as well as higher skew angle. The higher cutting position of $l_{x p} / l_{x}$ is disadvantageous to rock cutting.

(3) Negative exponential relationship exists between PCF and rock plate width and height. The $P$ value and $R^{2}$ value indicate that the regression analysis is reliable. Besides, the PCF increases and remains stable with the width, height, and cutting position and symmetrical with skew angle of zero degree.

(4) Considering the PCF and rock fracture morphology obtained in the paper, higher width, height, and lower skew angle are advantageous to rock plate cutting. With SPCF value, the minimum dimensions corresponding to minimum PCF cutting can be obtained.

\section{Data Availability}

The data used to support the findings of this study are included within the article.

\section{Conflicts of Interest}

The authors declare that there are no conflicts of interest regarding the publication of this paper.

\section{Acknowledgments}

This work was supported by the Natural Science Foundation of Shandong Province (Grants nos. ZR2019BEE069 and ZR2019MEE067) and Open Fund of Shandong Province Key Laboratory of Mine Mechanical Engineering (Grant no. 2019KLMM203).

\section{References}

[1] I. Evans, "A theory of the cutting force for point-attack picks," International Journal of Mining Engineering, vol. 2, no. 1, pp. 63-71, 1984.

[2] F. F. Roxborough and Z. C. Liu, "Theoretical considerations on pick shape in rock and coal cutting," in Proceedings of the Sixth Underground Operator's Conference, Kalgoorlie City, Kalgoorlie, Western Australia, Australia, pp. 189-193, October 1995.

[3] R. M. Goktan, “A suggested improvement on Evans' cutting theory for conical bits," in Proceedings of the Fourth International Symposium on Mine Mechanization and Automation, pp. 57-61, Queensland, Australia, October 1997.

[4] R. M. Goktan and N. Gunes, "A semi-empirical approach to cutting force prediction for point-attack picks," Journal of the South African Institute of Mining and Metallurgy, vol. 105, pp. 257-263, 2005.

[5] R. H. Bao, L. C. Zhang, Q. Y. Yao, and J. Lunn, "Estimating the peak indentation force of the edge chipping of rocks using single point-attack pick," Rock Mechanics and Rock Engineering, vol. 44, no. 3, pp. 339-347, 2011.

[6] X. Li, S. Wang, S. Ge, R. Malekian, and Z. Li, "A theoretical model for estimating the peak cutting force of conical picks," Experimental Mechanics, vol. 58, no. 5, pp. 709-720, 2018.

[7] S. Yasar, "A general semi-theoretical model for conical picks," Rock Mechanics and Rock Engineering, p. 2020. 
[8] N. Bilgin, M. A. Demircin, H. Copur, C. Balci, H. Tuncdemir, and N. Akcin, "Dominant rock properties affecting the performance of conical picks and the comparison of some experimental and theoretical results," International Journal of Rock Mechanics and Mining Sciences, vol. 43, no. 1, pp. 139-156, 2006.

[9] S. Yasar and A. O. Yilmaz, "Vertical rock cutting rig (VRCR) suggested for performance prediction of roadheaders," International Journal of Mining, Reclamation and Environment, vol. 33, no. 3, pp. 149-168, 2017.

[10] S. Yasar and A. O. Yilmaz, "Drag pick cutting tests: a comparison between experimental and theoretical results," Journal of Rock Mechanics and Geotechnical Engineering, vol. 10, no. 5, pp. 893-906, 2018.

[11] X. Wang, Q.-F. Wang, Y.-P. Liang, O. Su, and L. Yang, "Dominant cutting parameters affecting the specific energy of selected sandstones when using conical picks and the development of empirical prediction models," Rock Mechanics and Rock Engineering, vol. 51, no. 10, pp. 3111-3128, 2018.

[12] S. Yasar, "Determination of optimum rock cutting data through single pick cutting tests," Géotechnique Letters, vol. 9, no. 1, pp. 8-14, 2019.

[13] H. S. Li, S. Y. Liu, and P. P. Xu, "Numerical simulation on interaction stress analysis of rock with conical picks," Tunnelling and Underground Space Technology, vol. 85, pp. 231242, 2019.

[14] S. Wang, X. Li, K. Du, and S. Wang, "Experimental investigation of hard rock fragmentation using a conical pick on true triaxial test apparatus," Tunnelling and Underground Space Technology, vol. 79, pp. 210-223, 2018.

[15] L. Zhao, H. Liu, and W. Zhou, "A study on the dynamic transmission law of spiral drum cutting coal rock based on ANSYS/LS-DYNA simulation," Complexity, vol. 2019, pp. 1-14, 2019.

[16] A. Wang, J. Liu, Z. Liu, Y. Xia, J. Xia, and S. Qiao, "Establishment of coal-rock constitutive models for numerical simulation of coal-rock cutting by conical picks," Periodica Polytechnica Civil Engineering, vol. 63, 2019.

[17] X. Liu, P. Tang, Q. Geng, X. Li, and M. Tian, "Numerical research on wear mechanisms of conical cutters based on rock stress state," Engineering Failure Analysis, vol. 97, pp. 274287, 2019.

[18] S. Dewangan, S. Chattopadhyaya, and S. Hloch, "Wear assessment of conical pick used in coal cutting operation," Rock Mechanics and Rock Engineering, vol. 48, no. 5, pp. 2129-2139, 2014.

[19] D. Yang, J. Li, L. Wang, K. Gao, Y. Tang, and Y. Wang, "Experimental and theoretical design for decreasing wear in conical picks in rotation-drilling cutting process," The International Journal of Advanced Manufacturing Technology, vol. 77, no. 9-12, pp. 1571-1579, 2014.

[20] T. Stoxreiter, A. Martin, D. Teza, and R. Galler, "Hard rock cutting with high pressure jets in various ambient pressure regimes," International Journal of Rock Mechanics and Mining Sciences, vol. 108, pp. 179-188, 2018.

[21] L. Li, c. Tang, s. Tang, and P. A. Lindqvist, "Damage coupled thermo-mechanical model for rock failure process and applications," Chinese Journal of Theoretical and Applied Mechanics, vol. 38, no. 4, pp. 505-513, 2006.

[22] R. Comakli, "Effects of the physico-mechanical properties of low-strength pyroclastic rocks on cutter wear of roadheaders," Wear, vol. 428, pp. 205-216, 2019.

[23] D. Vogt, "A review of rock cutting for underground mining: past, present, and future," Journal of the Southern African
Institute of Mining and Metallurgy, vol. 116, no. 11, pp. 1011-1026, 2016.

[24] Z. Lu, L. Wan, Q. Zeng, X. Zhang, and K. Gao, "Numerical simulation of rock plate cutting with three sides fixed and one side free," Advances in Materials Science and Engineering, vol. 2018, pp. 1-21, 2018.

[25] G. R. Johnson, W. H. Cook, and W. H. Cook, "Fracture characteristics of three metals subjected to various strains, strain rates, temperatures and pressures," Engineering Fracture Mechanics, vol. 21, no. 1, pp. 31-48, 1985.

[26] Z. Lu, L. Wan, Q. Zeng, X. Zhang, and K. Gao, "Numerical simulation of fragment separation during rock cutting using a 3D dynamic finite element analysis code," Advances in Materials Science and Engineering, vol. 2017, pp. 1-17, 2017. 